\title{
Simon R. Rüegg and Barbara Häsler One Health continues to evolve for better health of people, animals and ecosystems
}

International policy makers, practitioners and the scientific community are committed to One Health $(\mathrm{OH})$ as recent financial, economic, social, environmental and health crises have led to the renewed recognition that collaborative approaches across disciplines, populations and sectors are needed to address such wicked problems. $\mathrm{OH}$ emphasises the commonalities of human, animal, plant and ecosystem health. With a human population that is projected to reach around 9 billion in 2050, ${ }^{1} \mathrm{OH}$ principles have become valuable not only for emerging diseases and zoonoses, but also for food safety, food security, malnutrition, microbial resistance to antibiotics, wildlife conservation, among others. ${ }^{2}$ In this perspective, the term can be used in lieu of many other integrated, and interdisciplinary approaches that tackle complex health challenges across systems in a holistic way to improve health for all, e.g. Ecohealth, Planetary Health, Global Health, or Health in scaled Social-Ecological Systems or Agrihealth. ${ }^{3}$

1 UN Department of Economic and Social Affairs: World Population (2020): https: / / population.un.org/wpp/Graphs/Probabilistic/POP/TOT / 900

2 E. P. J. Gibbs: The evolution of One Health. A decade of progress and challenges for the future, in: Veterinary Record 174/4 (2014) 85-91; C. D. S. Ribeiro, L. H. M. van de Burgwal, B. J. Regeer: Overcoming challenges for designing and implementing the One Health approach. A systematic review of the literature, in: One Health (2019) 100085.

3 T. Assmuth, X. Chen, C. Degeling, T. Haahtela, K. N. Irvine, H. Keune, R. Kock, S. Rantala, S. Rüegg, S. Vikström: Integrative concepts and practices 
There is considerable literature describing the characteristics of integrated approaches to health, but there is an ongoing debate as to the definition of $\mathrm{OH}^{4}$ viewpoints range from a clear focus on zoonoses, animal and human populations to a full systems approach that integrates any aspects of people, animals and ecosystems. During a project funded by the European Cooperation in Science and Technology (COST) between 2014 and 2018, over 250 scientists, decisionmakers and practitioners with expertise and/or interest in $\mathrm{OH}$ from more than thirty countries globally, set out to develop a framework to evaluate $\mathrm{OH}$. This Network for Evaluation of One Health $(\mathrm{NEOH})^{5}$ was inevitably confronted with the question of how to characterise $\mathrm{OH}$ to make it measurable for the purpose of evaluation. We set out to describe essential dimensions of $\mathrm{OH}$ that we would like to see in any initiative that considers itself to be $\mathrm{OH}$ and thereby move away from a philosophy to something more tangible. In the present article we describe the results from the work conducted during $\mathrm{NEOH}$ and in particular reflect on their significance in relation to our common practice in health.

\section{The Network for Evaluation of One Health (NEOH)}

As a first stepping-stone, the group generated a blueprint characterising $\mathrm{OH},{ }^{6}$ defining six essential dimensions, namely 1 ) thinking,

of health in transdisciplinary social ecology, in: Socio-Ecological Practice Research (2019): https:/ / doi.org/10.1007/s42532-019-00038-y

4 Ibid.

5 http://neoh.onehealthglobal.net

$6 \quad$ S. R. Rüegg, B. J. McMahon, B. Häsler, R. Esposito, L. R. Nielsen, C. Ifejika Speranza, T. Ehlinger, M. Peyre, M. Aragrande, J. Zinsstag, P. Davies, A. D. A. Mihalca, S. C. Buttigieg, J. Rushton, L. P. Carmo, D. De Meneghi, M. Canali, M. E. Filippitzi, F. L. Goutard, V. Ilieski, D. Milićević, H. O'Shea, M. Radeski, R. Kock, A. Staines, A. Lindberg, L. Rosenbaum Nielsen, C. Ifejika Speranza, T. Ehlinger, M. Peyre, M. Aragrande, J. Zinsstag, P. Davies, A. D. A. Mihalca, J. Rushton, L. P. Carmo, D. De Meneghi, M. Canali, M. E. Filippitzi, F. L. Goutard, V. Ilieski, D. Milicevic, H. O'Shea, M. Radeski, A. Lindberg: A blueprint to evaluate One Health, in: Frontiers in Public Health 5 (2017) 1-5. 
2) planning, and 3) working, supported by an enabling environment of 4) sharing, 5), learning, and 6) systemic organisation. We then developed a scoring system for the six dimensions to be able to measure the strength of $\mathrm{OH}$ (i.e. the One Health-ness) and compare it to the outcomes that the initiative produces. ${ }^{7}$ The network developed a tool to measure knowledge integration by means of a questionnaire with semi-quantitative scores for the six dimensions listed above. In a spider diagram, these six aspects span a hexagon whose surface we named $\mathrm{OH}$ index. The ratio between the surface spanned by the operational aspects and the surface covered by infrastructural aspects we named $\mathrm{OH}$ ratio. The index and ratio can then be compared to the ecological, economic, and social outcomes of an $\mathrm{OH}$ initiative to find out if a stronger or weaker One Healthness leads to better or worse outcomes. In addition, unexpected outcomes of the initiative are explicitly collected and included in the evaluation.

Crucial findings in this process were that 1) $\mathrm{OH}$ integrates knowledge from various sources in a transdisciplinary way and 2) that by the nature of the complex $\mathrm{OH}$ problems, the approach must employ system thinking. The first point posits that there are as many concepts of health as participants in a specific initiative, the second that we must consider emergences as an initiative is implemented. Conceptualising $\mathrm{NEOH}$ itself as an $\mathrm{OH}$ initiative, it was conducted as a participatory iterative process, during which, at annual intervals outcomes were shared and reflected, tested in case studies, and used to adapt the framework. It allowed engaging experts from various disciplines and sectors to contribute and help evolving the framework.

7 S. R. Rüegg, L. Rosenbaum Nielsen, S. C. Buttigieg, M. Santa, M. Aragrande, M. Canali, T. Ehlinger, I. Chantziaras, E. Boriani, M. Radeski, M. Bruce, B. Häsler: A systems approach to evaluate One Health initiatives, in: Frontiers in Veterinary Science 5 (2018) 1-18. 


\section{Outcomes of the network}

The primary outcome was a handbook for the evaluation of integrated approaches to health. ${ }^{8}$ First, we reflected on current practice in health governance and the opportunities opened by the UN Sustainable Development Goals for integrated approaches to health. This is followed by an evaluation framework and methodology to compare the effort invested into One Health-ness (or knowledge integration) to the outcomes anticipated by a theory of change in ecosystems, society and economy, and also considering unexpected outcomes emerging from the complex social-ecological system (SES) in which an $\mathrm{OH}$ initiative is situated. Evaluation in SES requires a good understanding of the dynamics within the system and its tangible as well as intangible elements. For example, cultural practices may have a major impact on alimentary habits, which may in turn affect the prevalence of diabetes and consequently need to be considered when aiming to address malnutrition. The framework explores qualitative and quantitative techniques, theories and models and associated metrics in three chapters focusing on ecological, social and economic aspects. The handbook concludes with a chapter on implementing a systems approach in the policy cycle. The second outcome of $\mathrm{NEOH}$ was a collection of case studies to which this framework had been applied. A brief description of the case studies is given in the following Table.

$8 \quad$ S. R. Rüegg, B. Häsler, J. Zinsstag (eds): Integrated approaches to health. A handbook for the evaluation of One Health, Wageningen 2018. 
Eight $\mathrm{OH}$ initiatives which were evaluated using the NEOH framework and that were compared for the present meta-perspective. Please see the references for more details on each initiative.

\section{Initiative description}

Comparison of brucellosis control in Malta and Serbia. Brucellosis is caused by zoonotic bacteria affecting ruminants, swine and other animals. The study historically describes and compares Malta's 1995-1997 with Serbia's 20042006 brucellosis control programmes and quantitatively assesses the extent to which they were compliant with a $\mathrm{OH}$ approach. ${ }^{9}$

Cysticercosis surveillance in Portugal. Human cysticercosis is a preventable feco-orally transmitted parasitic infection caused by cysticerci of the swine tapeworm T. solium. The study evaluates the design of the Observatory of Taeniasis and Cysticercosis, as an example of intersectoral collaboration for surveillance in Portugal. ${ }^{10}$

Southern African Centre for Infectious Disease Surveillance (SACIDS). The SACIDS initiative aims to promote a trans-sectoral approach to address better infectious disease risk management in five countries of the Southern African Development Community. Nine years after SACIDS' inception, this study aimed to evaluate the program. ${ }^{11}$

\section{Evaluation process}

Retrospective and comparative. 15 interviews and document analysis. Scored by focus group of 6 evaluators from both countries.

Prospective self-evaluation by 3 internal evaluators, reviewed by 3 external evaluators.

Formative, 9 years after inception of the centre. Document analysis, group and individual interviews, and online survey. Scoring by 2 evaluators, who resolved disagreements in discussion. Review by external evaluators.

9 S. C. Buttigieg, S. Savic, D. Cauchi, E. Lautier, M. Canali, M. Aragrande: Brucellosis Control in Malta and Serbia. A One Health Evaluation, in: Frontiers in Veterinary Science 5 (2018) 1-15.

10 A. G. Fonseca, J. Torgal, D. de Meneghi, S. Gabriël, A. C. Coelho, M. Vilhena: One Health-ness Evaluation of Cysticercosis Surveillance Design in Portugal, in: Frontiers in Public Health 6 (2018) 1-10.

11 M. C. E. Hanin, K. Queenan, S. Savic, S. R. Rüegg, B. Häsler: A One Health evaluation of the Southern African Centre for Infectious Disease Surveillance, in: Frontiers in Veterinary Science 5 (2018) 1-16. 
Mitigating health risks from reuse of acaricide containers in Southern Zambia. In this initiative, a transdisciplinary approach allowed for the identification of a serious public health risk arising from the unexpected reuse of chemical containers by the local public against advice. It was a satellite project to a program tackling production losses due to tick-borne disease in cattle in Southern Zambia in late 1980s. ${ }^{12}$

University of Copenhagen Research Centre for Control of Antibiotic Resistance (UCCARE) in Denmark. UC-CARE, a 4-year research project was a $\mathrm{OH}$ initiative with participants from 14 departments over four faculties as well as stakeholders from industry and health authorities aiming to produce new knowledge to reduce the development of antimicrobial resistance. ${ }^{13}$ West Nile Virus (WNV) surveillance in three regions of Northern Italy. This integrated surveillance program targets mosquitoes, wild birds, humans, and horses and aims at early detecting the circulation of $\mathrm{WNV}$ and reducing the risk of infection in the human populations. ${ }^{14}$ Obesity in European Dogs and DogOwners. A questionnaire-based study was carried out as a joint effort across 11 European countries. It was considered a
Retrospective, 25 years after initiative conclusion. Document analysis, and witness interviews. Scoring by external and internal evaluators.

Formative. Document analysis, semistructured interviews with 18 project participants, and stakeholder survey. Scoring by 2 internal and 2 external evaluators, validation at the centre's annual event.

Formative, several years after the initiative's inception. Interviews and questionnaires with involved actors. Scoring by 3 internal and external evaluators who resolved disagreements in discussion.

Formative self-evaluation, by 3 initiative participants. Online questionnaire with 20 questions to 24 participants of the initiative.

G. Laing, M. Aragrande, M. Canali, S. Savic, D. De Meneghi: Control of Cattle Ticks and Tick-Borne Diseases by Acaricide in Southern Province of Zambia: A Retrospective Evaluation of Animal Health Measures According to Current One Health Concepts, in: Frontiers in Public Health 6 (2018) 1-12.

13 A. L. Léger, K. Stärk, J. Rushton, L. R. Nielsen: A One Health evaluation of the University of Copenhagen Research Centre for Control of Antibiotic Resistance, in: Frontiers in Veterinary Science 5 (2018) 1-14.

14 G. Paternoster, L. Tomassone, M. Tamba, M. Chiari, A. Lavazza, M. Piazzi, A. R. Favretto, G. Balduzzi, A. Pautasso, B. R. Vogler: The Degree of One Health Implementation in the West Nile Virus Integrated Surveillance in Northern Italy, 2016, in: Frontiers in Public Health 5 (2017) 1-10. 
$\mathrm{OH}$ initiative between scientists from human and animal health sectors aiming to identify factors associated with obesity in dog owners and their dogs. ${ }^{15}$ Animal Welfare Center Skopje, Macedonia. The Animal Welfare Center in Macedonia was established in 2009. The objectives of the center are animal welfare $(A W)$ education, research, raising public awareness of $\mathrm{AW}$, and increasing cooperation between the stakeholders. ${ }^{16}$
Informal information exchange by mail and face-to face.

Formative self-evaluation, after 7 years of ongoing work. Scores averaged from 2 evaluators.

The development and the application of the handbook provoked many discussions in the network on aspects and conceptualisation of health, which we did not expect to encounter. This highlighted the importance of transdisciplinary work to identify knowledge gaps and foster innovation. At the same time the systematic framework allowed drawing conclusions about the added value of integrated approaches to health. In the following paragraphs we briefly outline the conclusions we drew from the case studies, and then mention the knowledge and conceptual gaps encountered as well as missing methods. Finally, the project being a dynamic system produced some unexpected outcomes that we would like to share.

\section{Conclusions from the case studies}

Currently, there is no benchmark available for the strength of $\mathrm{OH}$ and knowledge integration. We hope that the provision of the evaluation protocol as open access, training and raising awareness

A. Muñoz-Prieto, L. R. Nielsen, S. Martinez-Subiela, J. Mazeikiene, P. Lopez-Jornet, S. Savić, A. Tvarijonaviciute: Application of the NEOH Framework for Self-Evaluation of One Health Elements of a Case-Study on Obesity in European Dogs and Dog-Owners, in: Frontiers in Veterinary Science 5 (2018) 1-9.

16 M. Radeski, H. O'Shea, D. De Meneghi, V. Ilieski: Positioning Animal Welfare in the One Health Concept through Evaluation of an Animal Welfare Center in Skopje, Macedonia, in: Frontiers in Veterinary Science 4 (2018) 1-11. 
will help to accumulate case studies over time and will allow collating enough data to establish benchmarks.

To gain a first meta-perspective for the present paper, we compared the standardized evaluations according to the $\mathrm{NEOH}$ framework. Most data were available from the One Health-ness evaluations, but there were also partial evaluations of expected outcomes according to the theory of change, as well as descriptions of unexpected outcomes. Among the participating case study authors to date, there was consensus that employing a systems approach following the guidance provided widened the view on the projects and allowed a broader conversation about the underlying assumptions and expectations.

\section{One Health-ness and knowledge integration}

Project age appears to have an impact on the level of One Healthness, i.e. the extent to which an initiative facilitates knowledge integration and learning. Comparison of four case studies on infectious disease surveillance and control suggested that more mature initiatives become more holistic as they evolve in a trial and error process. ${ }^{17}$ A further case study was implemented as a satellite project of a mature development program deploying tick control in cattle. Because acaricide containers were used for food and water storage, this project was specifically implemented to prevent this behaviour. The good balance between all six evaluated aspects of knowledge integration suggests that it inherited the equilibrium from the original programme. However, the intensity in which knowledge integration and learning was facilitated was quite low, as suggested by the relatively small $\mathrm{OH}$ index. ${ }^{18}$

17 S. C. Buttigieg et al.: Brucellosis Control in Malta and Serbia, 1-15; M. C. E. Hanin et al.: A One Health evaluation of the Southern African Centre for Infectious Disease Surveillance; G. Paternoster et al.: The Degree of One Health Implementation in the West Nile Virus Integrated Surveillance in Northern Italy; A. G. Fonseca et al.: One Health-ness Evaluation of Cysticercosis Surveillance Design in Portugal. 
Knowledge integration and particularly the sharing of data is impacted by political boundaries. A phenomenon that has been reported for the governance of the sustainable development goals, ${ }^{19}$ can also be observed in $\mathrm{OH}$. The evaluation of an international effort for infectious disease surveillance showed that national as well as institutional borders are challenging for the sharing of data. ${ }^{20}$

The aspect of inter- and transdisciplinary work appeared to be the most challenging in the academic context. Two case studies embedded in an academic research context appeared to struggle with the coproduction of knowledge between different academic stakeholders. ${ }^{21}$ There seemed to be a disconnect between the ambition to work across disciplines and the cultural practice in science of evaluating achievements based on scientific, preferably high-impact publications. The latter put particularly junior scientists under pressure to produce disciplinary outputs that are highly cited, rather than reaching over disciplinary boundaries. The prospect of low citation rates in conjunction with the required effort to comprehend deeply a different perspective on the problem appeared to hinder true interdisciplinary implementation. Furthermore, the prevailing competitive mentality in academia was found to be a serious obstacle to trusted collaboration required for interdisciplinary progress. Nevertheless, a third case study evaluating an academic centre for animal welfare with a public mandate to improve animal welfare in Serbia showed a different picture. The explicit mandate to reach beyond academia and connect to practitioners resulted in a surprisingly good alignment with the $\mathrm{OH}$ concept. ${ }^{22}$

M. Nilsson, E. Chisholm, D. Griggs, P. Howden-Chapman, D. McCollum, P. Messerli, B. Neumann, A. S. Stevance, M. Visbeck, M. Stafford-Smith: Mapping interactions between the sustainable development goals: lessons learned and ways forward, in: Sustainability Science 13/ 6 (2018) 1489-1503. M. C. E. Hanin et al.: A One Health evaluation of the Southern African Centre for Infectious Disease Surveillance.

21 A. L. Léger et al.: A One Health evaluation of the University of Copenhagen Research Centre for Control of Antibiotic Resistance; A. Muñoz-Prieto et al.: Application of the NEOH Framework for Self-Evaluation of One Health Elements of a Case-Study on Obesity in European Dogs and Dog-Owners. M. Radeski et al.: Positioning Animal Welfare in the One Health Concept. 


\section{Expected outcomes from the case studies}

The case studies had a clear focus on applying and testing the new scoring for One Health-ness and therefore put most resources into this part; outcomes of the initiatives were largely included in a descriptive way and not measured formally. Nonetheless, positive outcomes from these projects were identified and it was hypothesised that partnerships spanning collaborators from government, academia and practitioner may generate more holistic solutions.

\section{Unexpected outcomes from the case studies}

The case studies were conducted to test the evaluation framework with a particular focus on the newly elaborated protocols for One Health-ness. Involvement of project stakeholders in the evaluation process was part of the evaluation method based on systems thinking. In fact, system thinking was an important foundation of the NEOH evaluation approach and was promoted in trainings and applications. Feedback from evaluators and project stakeholders showed that the NEOH framework was useful to look at initiatives in a fresh way and consider new perspectives. They asserted that systems thinking was challenging for many natural scientists and that considerable time and effort were required to attain a practical level of understanding.

In addition to being a tool for feedback and accountability, the evaluation process was recommended to conceptualise and plan new $\mathrm{OH}$ initiatives. This observation revealed that ultimately, a good $\mathrm{OH}$ initiative should consider the structures, processes and practices that are already in place in relation to a particular question by conducting an evaluation before the conception of further steps. It posits that we never start from scratch and always have some elements to build upon.

The NEOH evaluation tool for One Health-ness covers a broad range of aspects involved in knowledge integration. All case studies tended to be stronger in the operational aspects than in the provision of supporting environments, and no study had weaker operational aspects. At second thought this appeared quite logical as initiatives 
that foster data, method and knowledge sharing, learning infrastructure and systemic leadership would not necessarily consider themselves specifically as $\mathrm{OH}$. Consequently, there is a bias in initiatives that self-declare to be $\mathrm{OH}$ towards projects that overemphasise operational aspects over infrastructure, which can hardly be overcome.

Knowledge and conceptual gaps

The need for a scalable definition of health

Exchange across different disciplines and sectors in charge of different scales of life from microorganisms to national and global economies revealed a large variety of definitions of what is healthy. At the level of ecosystems, the concept of health per se is controversial. ${ }^{23}$ But also at individual level, our concepts of personal health are very diverse. Throughout the conversations, an emerging theme appeared to be that health can be regarded as a dynamic adaptive process rather than a static state. A potential framing would be health as resilience at individual level, with well-being and welfare as emerging properties of a functional co-adaptation between an individual and its direct environment. The concept of resilience can be evaluated at multiple levels of social-ecological systems (SES). Metrics for resilience are different at different scales, primarily because change occurs at much slower rates at larger scales and is faster at small scales, thus not allowing the same relative time resolution at all scales. Nonetheless, the principal idea can be transferred across all scales and can also accommodate for cultural differences.

Consequently, $\mathrm{OH}$ approaches would need to foster resilience at all scales, and as a minimal requirement not reduce resilience at any scale in an SES. This would allow people and non-human beings to evolve and allow adaption to various challenges at short and long term.

23 D. Rapport: Assessing ecosystem health, in: Trends in Ecology \& Evolution 13/10 (1998) 397-402. 
The need to balance between imposing health norms and relying on participation to tackle health challenges

Contemporary medical practice relies heavily on norms and references. A certain degree of deviation from a mean is commonly considered a pathology and regularity is a goal. Consequently, decision matrices are often objective, deterministic with the aim to re-establish normalcy. Similarly, in public health, veterinary public health and in food safety, solutions are often prescribed top-down, implying singular linear pathways in isolated aspects of health. There are obvious advantages of this approach when it comes to health management at scale, such as decision-making for resource allocation in a national health service. However, current health management is in stark contrast to the observation that complex systems show fractal behaviour and manifests in a coherent variation and diversity. ${ }^{24} \mathrm{~A}$ complex adaptive systems approach in medicine would require moving away from pre-established medical problems with expected solutions and working with people towards defining the medical goal itself. Such an approach requires of course an acceptance of unpredictability, uncertainty, and ambiguity ${ }^{25}$ - something most health care systems are not set up to deal with.

There is no doubt that norms and references have an important place in daily practice, but there is a risk that such norms may obliterate other potential pathways to health. In the context of $\mathrm{OH}$ the question arises to what degree such norms are universal and time independent, and to what degree they would require a contextualisation. While a strong focus on individual choice in health care with a consideration of people's perspectives has the advantage of more tailor-made health dynamics, the right to individualism stands in contrast with needs of communities or societies. When people make unhealthy choices, the health costs either result in a loss of solidarity because the community does not want to cover the consequences of

24 G. B. West: The importance of quantitative systemic thinking in medicine, in: Lancet 379/ 9825 (2012) 1551-1559.

25 R. Strand, G. Rortveit, E. Schei: Complex systems and human complexity in medicine, in: Complexus 2/1 (2004) 2-6. 
individual behaviour, or in rising health expenses for the community. Another example is the individual choice of vaccination, where people who may choose to abstain from vaccination contribute to lowering community or herd immunity and thereby increase disease risks. Here again, cohesion appears to be an important concept, i.e. solidarity needs to be reciprocal: while individuals consider the resilience of the community in their acts, the community can be solidary in return. However, it requires that health at various levels of the SES is discussed and co-produced. This shows that $\mathrm{OH}$ is more than an integrated approach to emerging infectious diseases, but a way to address many health concerns from malnutrition to traffic accidents in a participatory and inclusive process. The impacts are considerable as they affect legislation and require a fundamental overhaul of our cultural practice to compare individuals to a norm. Some possible approaches have been proposed such as social prescription, ${ }^{26}$ positive health dialogue ${ }^{27}$ critical complexity and participatory action research, ${ }^{28}$ or salutogenesis. ${ }^{29}$

A. Jani, M. Gray: Making social prescriptions mainstream, in: Journal of the Royal Society of Medicine 112/11 (2019) 459-461; A. Jani, E. Pitini, S. Jungmann, G. Adamo, J. Conibear, P. Mistry: A social prescriptions formulary: bringing social prescribing on par with pharmaceutical prescribing, in: Journal of the Royal Society of Medicine 112/12 (2019) 498-502.

M. Huber, M. van Vliet, M. Giezenberg, B. Winkens, Y. Heerkens, P. C. Dagnelie, J. A. Knottnerus: Towards a «patient-centred» operationalisation of the new dynamic concept of health: a mixed methods study, in: British Medical Journal Open 6/1 (2016) e010091.

28 J. L. Kincheloe: Critical Complexity and Participatory Action Research: Decolonizing «Democratic» Knowledge Production, in: D. Kapoor, S. Jordan (eds): Education, Participatory Action Research, and Social Change: International Perspectives, New York 2009, 107-121; P. Cilliers: Understanding Complex Systems, in: J. P. Sturmberg, C. M. Martin (eds): Handbook of Systems and Complexity in Health, New York 2013, 27-38. B. Lindström, M. Eriksson: Salutogenesis, in: Journal of Epidemiology \& Community Health 59/6 (2005) 440-442; B. Lindström, M. Eriksson: Contextualizing salutogenesis and Antonovsky in public health development, in: Health Promotion International 21/3 (2006) 238-244. 
The scission between benefits and threats from nature

Although $\mathrm{OH}$ acts as an integrating umbrella to talk about health, there appear to be two main opposing narratives around nature. One places emphasis on risks arising from nature such as infectious diseases, predators and pests, and is dominated by disciplines such as medicine, epidemiology and other health sciences. The other stream is concerned with the benefits of nature such as nature-based solutions against depression and allergies or ecosystem services, and is dominated by ecologists, sociologists, pedagogues or psychologists. There is increasing evidence that the microbiomes associated with exposure to nature are functional to produce these benefits. But even without explanatory causal links, a comprehensive conversation about the management of our environment requires a constructive dialogue between those two communities and viewpoints. To move from a struggle for prerogative of interpretation to a co-construction of understanding, it will be necessary to have more direct interaction and discourse between the different disciplines.

\section{Will egoism define the boundaries?}

Throughout conversations about participation in health governance, it became evident that the underlying assumption in $\mathrm{NEOH}$ was that, fundamentally, humans are willing to preserve their environment, are empathic and altruistic, beyond their generation and our own species to a degree sufficient to allow for a sustainable management. This assumption was contested by many people in and outside the network; often those less acquainted with participatory methods. It raises the question if participation requires some societal preconditions, which may not be given in highly individualised societies. Put in another way, participatory methods - as used successfully in the field of sustainable development - may help to make use of $\mathrm{OH}$ opportunities and to promote dialogue and solutions for intergenerational health if there is certain propensity among participants to engage, connect, reflect and change. It is expected, that economic activities that promote human well-being, sustainability and 
justice will need to be coupled with a steady-state in economic growth respecting planetary boundaries. This is essentially the premise of ecological economics. The future will show whether people are willing to rethink today's concept of prosperity driven by continuous increase in economic growth. Data show that the link between income and life-satisfaction is only linear up to a certain point. ${ }^{30}$ In some countries gross domestic product even contracts without a reduction of social parameters, such as unemployment rate. ${ }^{31}$ Given that the paradigm from which a system arises has a high leverage on the system outcomes, it appears intuitive that there are important drivers of well-being, health and disease rooted in our current shared values. ${ }^{32}$ It may be time for health professionals to engage in a broader conversation about societal values.

\section{What are the values associated to health?}

In the search for generic validity of concepts and frameworks, it goes unnoticed that we know very little about the lives of those who experience the complex entanglements between humans, animals, and ecosystems on a daily basis, and whose stewardship is decisive for change to occur. Although there are studies on more general values, ${ }^{33}$ particularly the comparative value of health for oneself, people, animals and ecosystems has not been explored.

Do we need a biocentric social justice framework?

During the exploration of the links between social sustainability and $\mathrm{OH}$, the importance of perspectives became also apparent for the notion of justice. While currently, with few exceptions justice is an anthropocentric notion, the aim of achieving interspecies health

\footnotetext{
30 A. E. Clark, S. Flèche, R. Layard, N. Powdthavee, G. Ward: The Origins of Happiness. The Science of Well-being over the Life Cycle, London 2018.

31 Personal communication: Erik Gómez-Baggethun, Norwegian University of Life Sciences citing CIA world factbook.

32 D. H. Meadows, D. Wright (eds): Thinking in Systems. A Primer, Chelsea VT 2008.

33 World Values Survey Association, World Values Survey, http:/ / www.worldvaluessurvey.org/wvs.jsp (accessed 28.02.2020).
} 
equity as an outcome of $\mathrm{OH}$, suggests that there may be a need to develop a framework for biocentric social justice.

\section{Methodological gaps}

Scalable participatory methods

So far, many participatory methods rely on workshops and group facilitation. In order to operationalize participation at larger scale, scalable tools must be developed. While these are available for, e.g. smart cities, in the field of $\mathrm{OH}$ this has not been developed. Furthermore, the call for transdisciplinarity would require interfaces from multiple perspectives and the facilitation of interactions across many social boundaries.

\section{The OH skill set}

While the skill set usually associated with public health, veterinary public health or conservation relies strongly on natural science, the observation in $\mathrm{NEOH}$ was that projects were rarely struggling with these. It appeared much more important to be equipped with skills unusual in the field such as non-violent communication, epistemology, history of science, macro-economics, system thinking, designing thinking, dealing with scales and non-equilibrium social sciences. Also, emphasis was put on reflection, dealing with ambiguity and uncertainty and critiquing own and others' paradigms.

\section{Alternatives to legislation and market mechanisms}

While we have discussed the concerns about the prescriptive nature of legislation earlier, market mechanisms are also failing to provide public health, animal welfare and environmental protection, as the latter are not restricted to tangible entities and not tradable. Impaired health and reduced resilience at all scales is often a result of cumulative behaviour. The current socio-ecological context does not seem to provide the appropriate feedback and incentives for sustainable behaviour. In the light of modern neuroscience and non-equilibrium social sciences, it appears to be an achievable 
target to reflect on the processes and features needed in an SES for all life to thrive. Solutions may be found in ecological economics where concepts of de-growth, green growth, and similar are discussed to provide alternatives to the prevailing increasing economic growth theory. Daly observed that beyond some point, growth is uneconomic and that multiple «illth» and the costs thereof can increase faster than wealth. ${ }^{34}$ Consequently, novel conceptualisations of growth and their measurement tools provide an opportunity for different narratives, research and strategies.

\section{Unexpected benefits from the project}

From the perspective of $\mathrm{OH}$ advocates the project has revealed that in other communities the wealth of literature on systemic approaches is growing rapidly and there are countless opportunities to cross-fertilise between different fields of application.

The COST Action generated a surprisingly strong interest. At its conclusion, over 250 participants were involved and interested in perpetuating the network beyond the funding period. It had formed a welcoming and highly inclusive community of practice with enormous potential for innovation. Many collateral conversations resulted in budding projects, and some of these conversations on framing, conceptualising and evaluating $\mathrm{OH}$ were captured in a dedicated eBook. ${ }^{35}$

The project had brought many participants to the edge of their comfort zone, exploring disciplines and settling with a new perspective on their practice. This has emphasized the importance of providing a safe space for experimentation, dreaming and failing.

34 H. E. Daly: The Illth of Nations and the Fecklessness of Policy: An Ecological Economist's Perspective, in: Post-Autistic Economics Review 22 (2003). Accessed 16.10.2020.

http:/ / www.paecon.net/PAEReview/issue22/Daly22.htm

35 S. R. Rüegg, S. C. Buttigieg, F. L. Goutard, A. Binot, S. Morand, S. Thys, $\mathrm{H}$. Keune (eds): Integrated Approaches to Health. Concepts and Experiences in Framing, Integration and Evaluation of One Health and EcoHealth, Lausanne 2019. 
It has revealed the tension between the academic and societal demands for infallibility and predictability versus the need for honesty, authenticity, humbleness and emotion to permit the full unfolding of human creativity.

\section{Acknowledgements}

This work was conducted in the frame of the COST Action TD 1404 «Network for Evaluation of One Health (NEOH)».

conexus $3(2020) 8-25$

(C) 2020 Simon R. Rüegg and Barbara Häsler. Dieser Beitrag darf im Rahmen der Lizenz CC BY-NC-ND 4.0 - Creative Commons: Namensnennung/ nicht kommerziell/keine Bearbeitungen - weiterverbreitet werden.

\section{(c) (1) (요)}

https:// doi.org/10.24445/ conexus.2020.03.003

Dr. Simon R. Rüegg, Universität Zürich, Vetsuisse Fakultät, Winterthurerstrasse 270, 8057 Zürich

srueegg@vetclinics.uzh.ch

Dr. Barbara Häsler, The Royal Veterinary College, Hawkshead Lane, North Mymms, Hatfield, Hertfordshire, AL9 7TA, United Kingdom bhaesler@rvc.ac.uk 